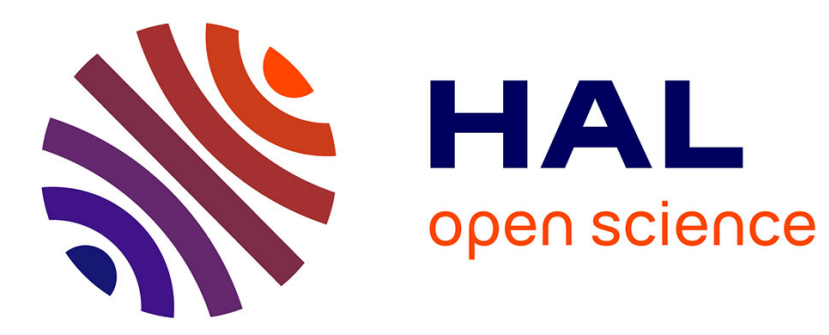

\title{
Une étude du contenu sémantique des prépositions por et para. Emplois et polysémie [Emplois et polysémie]
}

Dominique Neyrod, Y. Weller

\section{To cite this version:}

Dominique Neyrod, Y. Weller. Une étude du contenu sémantique des prépositions por et para. Emplois et polysémie [Emplois et polysémie]. Annexes des Cahiers de linguistique hispanique médiévale, 1988, Hommage à Bernard Pottier, 7 (1), pp.563-597. 10.3406/cehm.1988.2154 . hal-02147174

\section{HAL Id: hal-02147174 \\ https://hal.science/hal-02147174}

Submitted on 4 Jun 2019

HAL is a multi-disciplinary open access archive for the deposit and dissemination of scientific research documents, whether they are published or not. The documents may come from teaching and research institutions in France or abroad, or from public or private research centers.
L'archive ouverte pluridisciplinaire $\mathbf{H A L}$, est destinée au dépôt et à la diffusion de documents scientifiques de niveau recherche, publiés ou non, émanant des établissements d'enseignement et de recherche français ou étrangers, des laboratoires publics ou privés. 


\section{Une étude du contenu sémantique des prépositions por et para.}

\section{Emplois et polysémie}

\section{Emplois et polysémie}

Dominique Neyrod, Y. Weller

\section{Citer ce document / Cite this document :}

Neyrod Dominique, Weller Y. Une étude du contenu sémantique des prépositions por et para. Emplois et polysémie. In Annexes des Cahiers de linguistique hispanique médiévale, volume 7, 1988. Hommage à Bernard Pottier. pp. 563-597; doi : https://doi.org/10.3406/cehm.1988.2154

https://www.persee.fr/doc/cehm_0180-9997_1988_sup_7_1_2154

Fichier pdf généré le 12/01/2019 


\section{UNE ÉTUDE DU CONTENU SÉMANTIQUE \\ DES PRÉPOSITIONS POR ET PARA. EMPLOIS ET POLYSÉMIE}

* Los latinos abundan en preposiciones por las cuales distinguen muchas maneras de significar; e por que nuestra lengua tiene pocas es forçado que confunda los significados $>$ '

C'est à cette diversité de sens dont parle Nebrija que nous nous sommes intéressées dans le cas précis de por et para, en ne retenant de l'aspect syntaxique que la fonction de la préposition : établir des relations d'actance entre les participants impliqués dans un événement. Il nous a semblé utile d'envisager cette diversité de sens, de façon systématique, pour ces deux prépositions qui peuvent alterner dans certains cas, afin de définir de manière contrastive leur champ d'application sémantico-grammatical. Sur un corpus très varié, une analyse de leurs différents emplois a été faite dans le cadre plus large et abstrait des POTENTIALITES SEMANTIQUES ${ }^{2}$.

Nous appelons de la sorte le point de convergence auquel se rattachent divers emplois ; par exemple à la potentialité DIRECTIONINTENTION sont rattachés allatif, finalité, futur, etc...

C'est cette potentialité qui rend possible le fonctionnement de la préposition dans ces emplois.

Quatre potentialités ont été retenues :

1. - DIRECTION-INTENTION. Il y a ici l'idée d'une TENSION DIRIGEE qui peut être appliquée aux domaines spatial et temporel (en direction de, ou projection vers le futur), et au notionnel avec implication modale (intention).

2. - COINCIDENCE. C'est-à-dire SUPERPOSITION DES ZONES D'IMPLICATION des événements et des actants, par exemple locatif spatial et temporel, locatif notionnel de manière, de référence, etc...

3. - RELATIVITÉ. C'est une relation où l'un des termes - événement ou actant - SE DEFINIT au moins partiellement ou S'ACTUALISE PAR RAPPORT à l'autre. Cette potentialité ne donne lieu qu'à des emplois notionnels : attribution, adéquation, échange, etc...

4. - PUISSANCE. Signifie la FACULTE DE TRANSFORMATION et de création que possède un actant (puissant ou générateur de

1) Gramática Castellana (fol. 42 r. et v.).

2) Signifiance in posse $\gg$. 
l'événement) et qui s'exerce sur un autre actant (non puissant). A cette potentialité ne se rattachent que des emplois notionnels : agent et médiateur.

Y aurait-il lieu de dégager un plus grand nombre de potentialités ?

Dans cette étude les quatre potentialités proposées se sont avérées suffisantes pour rendre compte des emplois manifestés dans le corpus.

Ces emplois de por et para ont été décrits dans une perspective contrastive, chacun d'eux faisant l'objet d'une analyse des relations sous-jacentes qui permet de les relier aux potentialités.

L'analyse est représentée à l'aide des signes suivants, les prépositions /por/para/ étant indiquées sur les schémas, à droite de l'élément qu'elles modifient.

Act. $X, Y$, ou $Z=$ actants, participants de l'événement.

Ref. = référent.

(EV) = événement (peut aussi signifier une action) prédicatif ou non-prédicatif.

$\mathrm{K}=$ caractéristique ou qualité.

Jug. = modalité de jugement.

Potentialités

Sémantiques

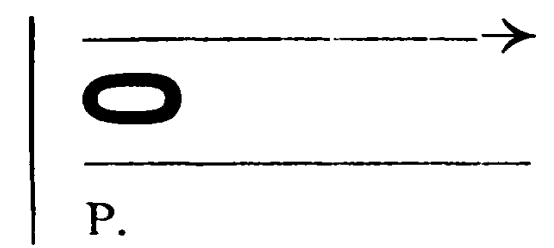

DIRECTION-INTENTION COINCIDENCE RELATIVITÉ PUISSANCE

Cette démarche pose donc trois niveaux d'abstraction qui s'interpénètrent : emplois, analyse des relations et potentialité sémantique. Elle permet d'organiser autour de quatre thèmes la luxuriance et la complexité des occurrences de ces prépositions, ce qui s'avérerait impossible si l'on ne se reposait que sur des critères syntaxiques. En effet la part de la syntaxe se limite à ce qui est exprimé dans le terme même de préposition, ce relateur précédant toujours l'élément qu'il modifie $^{3}$.

Dans cet esprit de recherche et d'identification des potentialités sémantiques, il était logique de travailler sur un corpus dépourvu de toute contrainte de temps et de lieu. Les emplois répertoriés sont en usage depuis le $\mathrm{XvI}^{\mathrm{e}}$ siècle, sur toute l'étendue de l'Hispanité. Les variétés dialectales sont comprises par tout hispanophone (même comme formes marginales qu'il n'emploie pas). Les exemples choisis librement, suivant notre plaisir, sont pour la plupart empruntés à des écrivains espagnols et hispano-américains, à des textes judéo-espagnols, au répertoire populaire, traditionnel, religieux, familier ou savant :

3) Dans un air traditionnel du Sud du Pérou (Cuzco), para apparaît systématiquement en fin de proposition.

$$
\begin{aligned}
& \text { Así se canta, asi se baila para, (bis) } \\
& \text { Para robar corazones para (bis) }
\end{aligned}
$$

La possibilité d'isoler ainsi la préposition du terme sur lequel elle porte est amenée par la ponctuation rythmique du huayno (structure de chant-danse) et par le contact avec le quechua, ou la finalité est marquée par un suffixe. 
CONTENU SÉMANTIQUe DES PRÉPOSITIONS « POR 》 ET «PARA 》 565 récits, dialogues, chansons, journaux, B.D., etc... Ceux qui ne font pas l'objet d'une référence ont été entenđus, attestés et contrôlés par témoins, ou font partie de notre propre stock linguistique en langue maternelle.

\section{I - Potentialite semantique DiRECTION-INTENTION.}

La présence de DIRECTION-INTENTION dans les deux prépositions rend possible les emplois suivants dans les domaines spatial, temporel et notionnel.

1. Domaine spatial.

Para

Emploi : Allatif

(1) Cuando pa' Chile me voy cruzando la Cordillera, late el corazón contento una chilena me espera.

(2) La Casilda no tiene corazón. La última noche que pasamos juntos me dijo que yo andaba para viejo.

Analyse de la relation :

$$
\text { Act } X(\mathrm{EV}) \longrightarrow \text { Act } \mathrm{Y} \text { /paral }
$$

Commentaire :

L'allatif est lié au signifié « mouvement » du lexème verbal.

Por

Allatif

(3) En arribando sobre el Kei, elya embezó ke abía una nabe en partensya después de tres días por Benezya.

(4) Sí - respondyó Melita - yo sé ke partes por Mayans $i$ te sueto un buen biaže.

Dans ces deux exemples ( 3 et 4) por marque cet emploi de façon tout à fait exceptionnelle et non attestée hors de cette variété de judéoespagnol ${ }^{3 b i s}$. Remarquons qu'il s'agit vraisemblablement d'un calque du français (pour, allatif) c'est-à-dire d'une manifestation de ce qui a été appelé judéo-fragnol par Haïm Vidal Sephiha. Sinon, pas d'emploi de por en relation avec cette potentialité dans le domaine spatial.

$3^{\text {blo) }}$ Džudezmo de Turquie (xTx'). 
2. Domaine temporel.

Para

Pré-Inchoatif

(5) Estaba para llover cuando se aparecieron los campesinos. Llegaron corriendo. Iban armados de palos y hondas y algunos gritaban : i qué salga el alcalde!

(6) Cuando alcanzamos el puentecito, reparamos que el pedrón estaba para caerse.

(7) Corre y avisale que ya debe estar para marcharse.

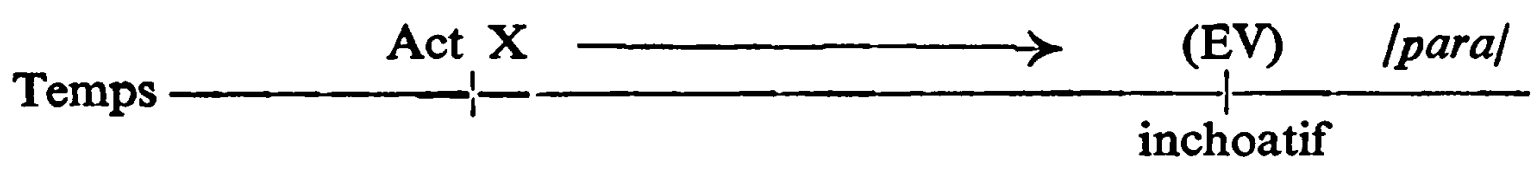

L'expression verbale ESTAR para + INFINITIF peut avoir divers types de sujets (humain, non humain, impersonnel) ; dans tous les cas, le pré-inchoatif renvoie à une tension vers un futur caractérisé par l'événement. Si c'est un humain agissant l'intentionalité intervient.

Futur d'obligation

(8) - Mujer qué hay en el costal, - que está contra la pared?

- Ese costal, mi marido, - es trigo para moler. $>$

Abrió el costal y miró - sombrero del padre cura.

- Buenos días padre cura... - padre cura por moler ! s

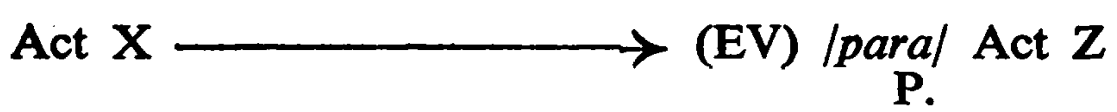

Cet emploi ne s'inscrit pas en déixis temporelle mais associe la notion de futur à celle modale, d'obligation. L'auxiliaire est un verbe statique (tener, seguir, quedar, estar, etc...), la distinction avec le pré-inchoatif étant liée à la notion de puissance : ici, le sujet subit l'action et l'actant agissant $n$ 'est pas exprimé. On remarque dans l'exemple l'opposition para, futur d'obligation, et por, finalité.

Dans le cas de :

(8 $\left.{ }^{\text {ble }}\right)$ Estoy cocinando para mi pastel. Voy a buscar para mi camino.

(Paraguay, Corrientes et Misiones) 4 , on serait devant une structure de bénéfactif si l'on se référait à la norme de la langue castillane ;

4) Cf. Rafael Lapesa et communication personnelle de Rubén Bareiro Saguier. 
CONTENU SÉMANTIQUE DES PRÉPOSITIONS «POR 》 ET « PARA 》 567

en fait, para marque ici le futur, selon un emprunt à la syntaxe du Guaraní, où les temps (futur, passé) peuvent être marqués sur les nominaux. (On pourrait paraphraser : estoy cocinando lo que va a ser mi pastel, voy a buscar el camino por el que voy $a$ ir).

En outre, le verbe et le nominal marqué para ont le même indice de personne.

Por

Pré-Inchoatif

(9) Vamos a ver aquel buque, - que está por naufragar; con sus banderas peruanas, - imi vida! esta or naufragar.

(10) La jora está por hervir. Baja la candela, iremos sacando las isancas.

(11) Tocaron la aldaba cuando estaba por preparar el aderezo.

L'expression ESTAR por + INFINITIF relève de la même analyse que celle du pré-inchoatif avec para, mais comporte une plus faible part d'intention ou d'immédiateté. Ainsi, d'une façon générale partout où l'on a ESTAR para (pré-inchoatif) on peut entendre ESTAR por, le contraire n'étant pas vrai. Cf. $(9,10)$.

\section{Inchoatif}

(12) No te escuchó... parece que estuviera rezando. Sólo falta que le dé por la locura mistica.

(13) En la época de la rivalidad... a mi amigo le dio por dramatizar las cosas. Vinieron a contarme que preparaba un duelo... en un cementerio.

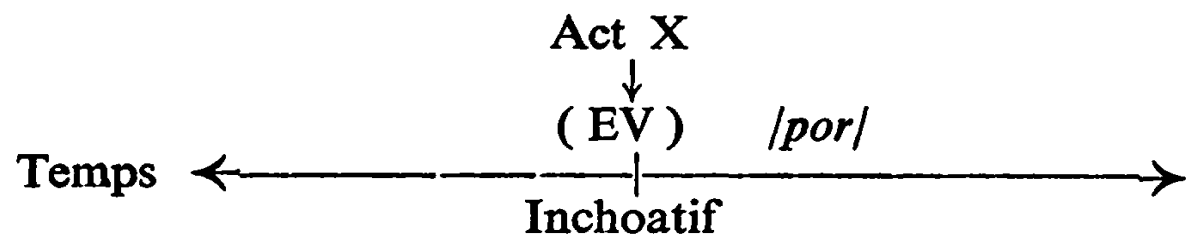

L'expression verbale DAR por + INFINITIF relève à la fois du temporel et du modal, elle implique donc en même temps le commencement d'un événement et une forte intentionalité de l'actant $\mathrm{X}$ sur l'événement.

Futur.

(14) Yo quisiera ser de quince años y más hermosa que Lucrecia para servir con todos mis bienes habidos $y$ por haber a vuesa merced. 
(15) Es moza de chapa, hecha y derecha y de pelo en pecho, y que puede sacar la barba del lodo a cualquier Caballero andante o por andar que la tuviere por señora.

(16) $Y$ sin salirnos aún de los diversos grados de formalización nos queda por examinar un caso que no ha sido adecuadamente interpretado.

(17) Y mire Ud, Don Rafaelito, lo que son las cosas, mi hija María está por merecer. Es más tonta! En cambio aquella ha pescado un novio rico.

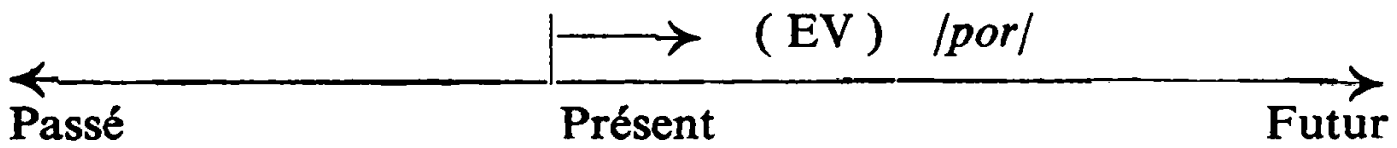

La préposition por peut marquer la réalisation d'un événement dans le futur (sans autre précision), $(14,15,17)$. L'expression QUEDAR por (ou autre auxiliaire) + INFINITIF ajoute le sens spécifique d'obligation (16).

\section{Domaine notionnel.}

Dans ce domaine les emplois plus nombreux et variés qu'en spatio-temporel, peuvent découler à la fois des potentialités DIRECTION-INTENTION, COINCIDENCE ou PUISSANCE. Afin de faire ressortir les similitudes et les contrastes entre les emplois de por et para recouvrant les notions de finalité, causalité, et bénéfactif, ceux-ci seront présentés ensemble.

Para

Finalité.

(18) Mi voz buscaba el viento para tocar su oido.

(19) Le construyó a su mujer un dormitorio sin ventanas para que "no tuvieran por donde entrar los piratas de sus pesadillas.

(20) Ese fulano para día y noche en las cantinas del barrio chino pa' que sepas.

(21) En las huacas uno encuentra... ovillos y madejones despepitados que parece que los hubieran puesto ahi, junto con sus muertus, para seña o vaya uno a saber con qué finalidad.

5) Nous ne tiendrons pas compte ici de la différence syntaxique établie par la grammaire traditionnelle entre prépositions et conionctions de subordination, car notre travail se place dans une perspective résolument sémantique (cf. à ce sujet, Frei, Pottier, Trujillo, etc...). 
CONTENU SÉMANTIQUe DES PRÉPOSITIONS « POR 》 ET « PARA 》 569

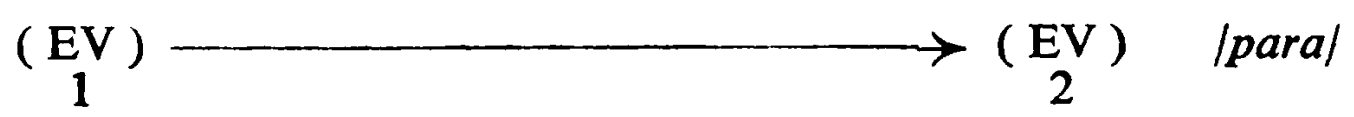

Deux événements sont mis en relation dans une perspective chronologique, l'un marqué para succédant à l'autre.

D'autre part, il y a tension et intention vers l'événement 2 du ou des actants impliqués dans l'événement 1. L'exemple 21 paraphrase clairement le sens finalité de para.

Des lexies telles que para que veas, ou para que sepas, tout en gardant à la base leur sens final, fonctionnent comme des modalités d'assertion (20).

Por

Finalité.

Voir plus loin, exemples 30, 31, 32.

Causalité.

(22) POR un perro que maté, Mataperros me llamaron y Mataperros me quedé. Por una vez que quité la cola al burro me llamaron Descolaburros.

(23) A Pedro de Utría el viejo, por ser calvo y denegrido,

por berenjena socata;

por cañafístola al hijo,

por papaya a doña Elvira,

$y$ por badea al Elviro.

(24) Juan de Maïrena... usaba un gabán bastante ramplón que él solía llamar la venganza catalana, porque era de esa tela, fabricada en Cataluña que pesa mucho y abriga poco.

(25) Lendl vive por y para el tenis y piensa que la vida empieza y termina en el tenis.

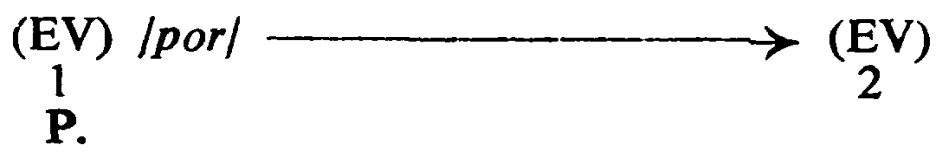

Deux événements sont mis en relation dans une perspective chronologique mais contrairement à l'emploi de para finalité, c'est l'événement 1 qui est marqué par la préposition. Dans l'exemple 25 cette chronologie est paraphrasée : por (causalité) : empieza ; para (finalité) : termina. Par ailleurs, la fonction causative dépend du potentiel PUISSANCE contenu dans por. Cette fonction n'est pas toujours assumée par un événement, elle peut l'être aussi par un actant, par exemple : 
(26) Carcelero,

Aquí me encuentro encerrado por unos ojitos negros...

(26 ${ }^{\text {bis})}$ Por muy dichoso se tenga quien por vos sufre pasión pues es harto galardón.

Causalité intentionnelle

(27) Así hubiera abandonado una cigüieña un niño en la cama de una soltera, por equivocación, por cansancio, por broma .

(28) Estudio el quechwa por conocer el origen de mi pais y por poderme entender con la gente, ya que me sentía extranjera cuando trabajaba en Puno.

(29) Yo siempre pico el tabaco por no pitarlo aventao.

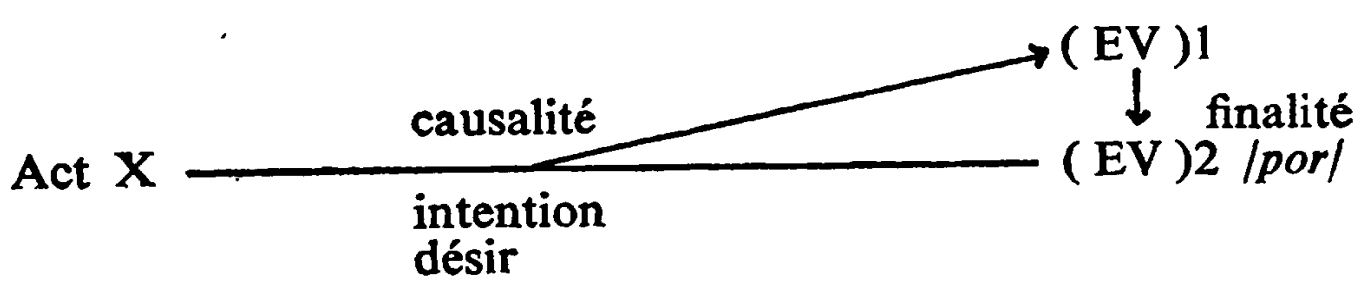

Cet emploi présente un triple mouvement intentionnel, un vouloir de X sur l'événement 2 (no quiere pitar el tabaco aventado) (29). Ce vouloir est la cause de l'événement 1 (picar el tabaco), lequel se réalise en vue de l'événement 2 (pitarlo).

Il faut donc dans cet emploi distinguer deux types de chronologie. L'une observable, où l'événement 1 est antérieur à 2 ; 1'autre non observable, où l'intention relative à 2 est antérieure à 1 . C'est dans le cadre de cette dernière chronologie que l'événement 2 est marqué por. Il convient ainsi de mettre en contraste l'emploi de para (finalité) et celui de por (causalité intentionnelle).

Alors que para ne marque que la finalité, la préposition por parcourt un axe sémantique continu, allant de la finalité (où elle alterne sémantiquement aussi bien que syntaxiquement avec para, exemples 30 et 31$)^{7}$ au locatif notionnel $(33,34)$, en passant par le causatif intentionnel, comme on vient de le voir.

6) Les deux premiers por sont de causalité et le dernier marque l'intentionalite supplémentaire. Il est entendu que dans tous les exemples à venir, seule la préposition soulignée nous intéresse pour l'analyse.

7) En castillan classique, c'est por qui marquait régulièrement la finalite; para l'a remplacé peu à peu dans cet emploi (cf. Menéndez Pidal, Hanssen, Lapesa). De nos jours l'alternance por $\sim$ para est illustrée entre autres, par les deux formes simultanément attestées du proverbe:

$$
\text { No hay mal que }\left\{\begin{array}{l}
\text { por bien no venga. } \\
\text { para }
\end{array}\right.
$$


CONTENU SÉMANTIQUE DES PRÉPOSITIONS «POR » ET «PARA» 571

Les exemples suivants 'montrent l'emploi de por finalité.

(30) Vengo para gozarte, bello amante, vengo por remorir entre tus brazos.

(31) Sabes tú muy bien que para lograr lo que yo pretendo, daría por lt mi vida y mi ser, solo por amarte.

(32) ¿O cuál es más de culpar, aunque cualquiera mal haga la que peca por la paga o el que paga por pecar?

En dehors de toute perspective chronologique l'emploi locatif notionnel de por découle de l'association des potentialités DIRECTION-INTENTION et COINCIDENCE.

En causalité intentionnelle l'alternance por para est syntaxiquement possible et n'apporte qu'une différence sémantique légère, qui n'affecte pas le sens général de l'énoncé $(27,28,29)$.

Au contraire en locatif notionnel, lorsqu'elle est syntaxiquement possible l'alternance conduit à une modification du sens même des lexèmes. Ainsi dans l'histoire drôle de ce vieil homme qui demande à être enterré loin de la ville où il se trouvera le jour de sa mort (« Si c'est à San Sebastián, qu'on m'enterre à Málaga, si c'est à Cádiz, qu'on m'enterre à Barcelone, etc... etc...) et qui répond quand on lui en demande la raison :

(33) Pues nada... i Por joder, hijo, por joder!

Ici, avec para, le sens du lexème verbal serait autre, sa valeur stricto sensu serait maintenue.

Remarquons un continuum entre le causatif intentionnel et le locatif notionnel comme le montrent l'exemple 34 et sa paraphrase en 34bis, qui font également ressortir l'opposition entre causatif intentionnel (por) et finalité (para).

(34) Frustrado, chupas no por divertirte sino para sumirte en tu infelicidad.

(34 ${ }^{\text {bia }}$ No se tomaba los piscos como alguien que quiere divertirse sino buscando emborracharse rápido.

Outre cette paraphrase en causalité intentionnelle por divertirse peut l'être en locatif notionnel de manière : a modo de diversión.

Multiples autres exemples : por las puras, por gusto, por pura gana, por palangana.

Concession.

(35) Por muy santo o muy santa que se suponga ser, nadie sin compañia quiere permanecer. 
(36) No hay manjar por preciado que sea, que no empalague, ni vicio que no harte.

$\left(\begin{array}{l}\mathrm{EV} \\ 1\end{array}\right.$ |por|

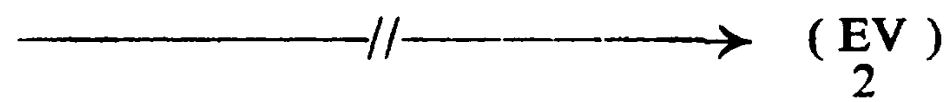

La relation de cause à conséquence entre les événements est invalidée ${ }^{8}$, l'événement 1 marqué por étant refusé en tant que cause de l'événement 2. Dans cet emploi por apporte un élément d'intensité et se trouve de plus fréquemment associé à un intensif : por mucho que, por más que, et (35).

Para

Bénéfactif.

(37) Una piedra en que sentarme ¿ no habrá ahora para mí? Yo digo para mi : por fin escapo al ruido...

(38) Supimos todos en el pueblo que la profesorita habia tenido un hijo para el niño Jorge.

(39) Demetrio mandó traer un pellejo de tinto para todos nosotros y para invitar a sus clientes de la tasca. Act Y /paral

Cet emploi découle du seul potentiel DIRECTION-INTENTION et répond au même schéma d'analyse que l'allatif (voir plus haut). Il se rapproche sémantiquement de l'emploi finalité ; la différence étant que le terme d'une intention bénéfactive est toujours un actant alors que le terme d'une intention de finalité est toujours un événement même sous-entendu. (cf. exemple 39 : para todos nosotros, bénéfactif, para invitar a sus clientes, finalité).

Signalons la lexicalisation parabién : No entendiamos el peligro... así, cuando llegamos a tierra todos nos daban el parabién a las vidas.

Por

Bénéfactif.

(40) Arvoles yoran por lluvias $y$ montañas por ayres ansi yoran los mis ojos por ti, querida amante.

(41) Esta lana es de la que dicen los españoles que vuelve trasquilado quien viene por ella. 
CONTENU SÉMANTIQUe DES PRÉPOSITIONS «POR » ET « PARA » 573

(42) Pocos criollos en Venezuela creen que luchar por la independencia del país es hacerlo por la libertad.

(43) Santa María, Madre de Dios ruega por nosotros pecadores, ahora y en la hora, etc...

(44) La negra re mi arma mia,

Mientrá yo brego en la má, bañaro en suró por ella

qué hará? qué hará?

Le bénéfactif se situe sur un continuum qui va de la finalité à la causalité. Les emplois qui tendent à la finalité sont marqués para ou por ; ceux qui tendent à la causalité sont marqués por. Ainsi dans :

(45) Yo no soy marinero, por ti seré, por ti seré...

substituer para à por ne donnerait pas l'idée de causalité mais celle de jugement. ( me verás como marinero »).

Par ailleurs, il n'est pas inintéressant d'opposer à cet exemple bénéfactif à tendance causale), un exemple de véritable cau salité.

(46) Por una magajica semos gidiós.

Dans le bénéfactif avec para $(40,41,42)$, le terme marqué est directement bénéficiaire de l'événement, l'idée de destination est plus proche de la finalité. Avec por, le bénéfice est plus médiatisé. Cf. hazlo para mí/hazlo por mi, reza por mí, habla por mí (en mi nombre).

Le schéma suivant illustre ce continuum :

Finalité

Causalité

/para/ ex. 37, 38, 39

|porl ex. 40, $41 \ldots \ldots \ldots \ldots$ - $\ldots 2,43 \ldots 22,23,24,25,44$

Il faut souligner que dans la zone sémantique couverte à la fois par por et para l'usage de l'une ou l'autre de ces prépositions dépend très fortement du contexte et de l'intention du locuteur (cf. El Che Guevara luchaba por/para el pueblo).

Cependant le sens spécifique de recherche (toujours associé à un mouvement) ne peut être marqué que por $(41,47)$

(47) Lo primero que hizo mi ama fue darme un cantaro y mandarme por agua.

Dans cet emploi la préposition $a$ peut être préposée à por (Péninsule).

(48) Estuve (en Sicilia) 16 meses y tuve algunos encuentrillos con moros de los que venían a por carne $y$ agua. 
(49) i Las gafas! Carmen fue a por ellas y se las puso.

\section{II - Potentialite semantique COINCidence.}

1. Domaine spatial.

Para

Aucun emploi en liaison avec la potentialité COINCIDENCE. Por

\section{Locatif spatial.}

(50) Del puente a la Alameda, menudo pie la lleva por la vereda que se estremece al ritmo de su cadera.

(51) Y yo haría lo que quisiera - irme por las calles que a esa hora huelen a miel de Chancaca y a estropajo de cocina...

(52) Todos somos cantores, todos hacemos de garganta. No fuimos en nuestro canto por terceras, quintas ni octavas, sino cantando a un tiempo todos ocho tonos y más otros medios tonos y cuartas.

(53) Tabla, tabla ; Señor capitán y maestre y buena campaña. Viva, viva el Rey de Castilla por mar y Por tierra! Quién le diere guerra que le corten la $\overline{c a b} e z a$.

(54a) Hace siglos que no nos vemos, hermano ¿Cuando

b) te vienes por casa? No te vayas a confundir. Ahora vivimos por la iglesia, a media cuadra...

(55) Yo no soy de por aquí vengo de por allá lejos

donde rendimos las novias con secreticos y besos.

(56) «alla \& ejecutó el volapié con todas las de la ley, perfilándose en corto y por derecho, sobre el pitón contrario... y saliendo limpio por el costillar como dicen que lo hacía el mentado Joaquín Rodríguez « Costillares ».

(57) Por entre mis propios dientes salgo humeando, dando voces, pujando...

La miseria me saca por entre mis propios dientes, cogido con un palito por el puño de la camisa.

(58) Se ponen a cocinar los frejoles sin sal y en cuanto estén, se les pasa por un colador muy fino, junto con la leche hasta formar una pasta fina. 
CONTENU SÉMANTIQUE DES PRÉPOSITIONS «POR 》ET «PARA » 575

\section{Act $\mathbf{X}$}

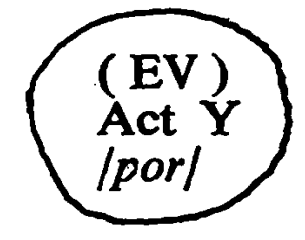

L'événement lié à l'actant $\mathrm{X}$ se déroule dans l'espace de l'actant $Y:$ il y a coïncidence spatiale.

Por marque soit l'occupation partielle $(50,51,52)$ ou totale $(53,54 a)$ de l'espace, soit une localisation approximative $(55,56)$, soit l'abessif $(54 b)$, soit le transit $(57,58)$.

En (54a) la juxtaposition d'un verbe de mouvement et d'un locatif spatial donne globalement un sens d'allatif qui s'exprime à travers une structure non allative.

Un exemple intéressant de por marquant l'occupation de l'espace est celui de año por medio (ou día, semana...). La locution prépositionnelle por medio appartient au domaine spatial mais fonctionne dans un contexte temporel ; l'espace entre deux périodes marquées par un événement est régulièrement occupé par une pause : un año si, otro, no.

Signalons encore la locution prépositionnelle por debajo dont dérive le verbe pordebajear (Bogotá).

2. Domaine temporel.

Para

Locatif temporel.

(59) Ahi tiene Vd. Don Rafaelito... La flaca! , Pues ha pescado un novio rico con el que va a casarse para fines de año!

(60) Para entonces Gala y Dali residen en los EE.UU.

Act $X$

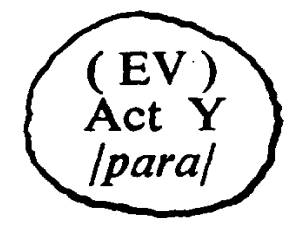

Dans cet emploi, para est associé d'une part à une détermination temporelle ponctuelle, d'autre part à un événement passé ou à venir ; avec ce dernier, il implique une localisation approximative et peut intégrer un élément d'intentionalité.

Por

Locatif temporel.

(61) Por esas fechas volvió a presentar problemas el embajador de Haïti. Amaneció un día dando gritos...

(62) Por abril, corta un cardo y nacerán mil.

(63) Zamba del amanecer, arrullo de Balderrama, Canta por la media noche y llora por la madrugada. 
(64) Por momentos pienso dar en la coyuntura de la ver$\overline{d a d} y$ por minutos me hallo tan lejos della que vuelvo a subir al monte que acabé de bajar, con el canto de mi trabajo a cuestas, como otro nuevo Sisifo.

(65) Fundaron luego 12 ranchos pajizos que bastaban por entonces para recoger la gente toda.

(66) Epa! te pasas de maraca. Por de pronto ensilla el caballo y espéranos en el patio.

Cet emploi de por répond à la même analyse que son correspondant avec para. Mais il faut souligner que por peut être associé également à un événement présent (66).

Quand la détermination temporelle est imprécise, por marque l'approximation (61).

Si le lexème implique une certaine durée tout en restant une détermination ponctuelle $(62,63,64)$, l'approximation joue à l'intérieur de cette durée. En (64), l'association de cette caractéristique et de la pluralité marque une localisation temporelle discontinue.

Si la détermination est plus précise, por perd l'implication d'apporximation et fait apparaître un élément intentionnel (65 et $66: \grave{a}$, en ce moment, en ce qui concerne ce moment).

Para

Duratif.

(67) ... la bisabuela de Ursula... se sentó en un fogón encendido. Las quemaduras la dejaron convertida en una esposa inútil para toda la vida.

(68) Kedaron kazados para syen i un anyo, de dos azeytunikas se fizyeron tres.

(69) Levanten la tumba

levántenla ya

que el alma se ausenta

pa' nunca jamás.

(70) Mi viejo Buenos-Aires, qué lindo que has d' estar, Ya van para diez años que me viste zarpar.

Avec une détermination temporelle de durée, le sens duratif se joint au locatif (voir développement dans por duratif.).

Remarquons qu'en (70) c'est une durée approximative qui s'exprime à travers le schème d'allatif, le point d'arrivée étant "diez años » envisagés comme durée révolue et ponctualisée.

Por

Duratif.

(71) El ajiaco se deja al fuego por hora y media sin que deje de hervir. 
CONTENU SÉMANTIQUE DES PRÉPOSITIONS «POR 》 ET « PARA 》 577

(72) Por siempre sea alabado el Santisimo Sacramento, $\overline{\text { Por }}$ los siglos de los siglos alabada su deidad.

(73) Vaya, vaya con los tortolitos! que sea por muchos años y que todos lo veamos.

Dans l'expression de la durée, por marque l'espace temporel considéré dans sa totalité, du début à la fin (d'où la non-occurrence avec nunca). Espace qui peut être explicite (71) ou implicite $(72,73)$.

Por s'oppose ainsi à para, qui marque le départ du parcours de l'espace temporel, lequel reste implicite. Dans l'exemple (68) «syen $i$ un anyo » symbolise une durée longue et non explicite (para siempre).

Ces deux visions de la durée peuvent être représentées ainsi ${ }^{\bullet}$ :
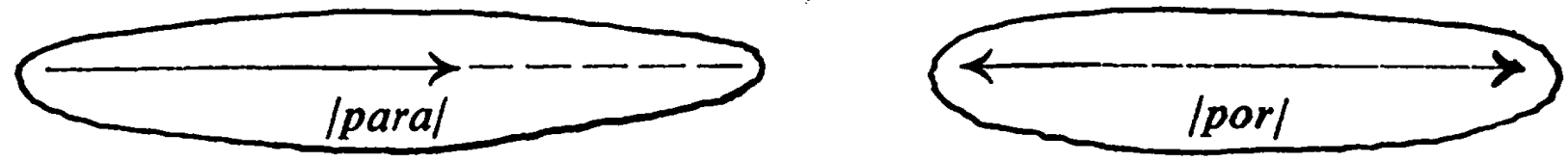

$\emptyset \ldots \ldots \ldots \ldots \ldots \ldots$ por dos horas

para rato ................ por un rato

para toda la vida ............ por toda la vida

$\emptyset \ldots \ldots \ldots \ldots \ldots \ldots \ldots$ de por vida

$\emptyset \ldots \ldots \ldots \ldots \ldots \ldots \ldots \ldots$ por la eternidad

para siempre ............. por (siempre) (jamás)

para nunca jamás ......... Ø

3. Domaine notionnel.

Para

Un seul emploi, référence (voir, por : référence).

Por

Locatif notionnel.

Manière.

(74) Un cuerpo de tropas del ejército imperial tomó por asalto el 26 por la mañana el pueblo de Vantzenau, a una legua de Estrasburgo.

(75) Por fortuna, el libertador Bolivar era hombre de no asustarse con duendes ni musarañas.

(76) Pedro I mato muchos en su seguro, por lo cual le vino todo el daño que avedes oído. Por ende, diremos aquí lo que dijo el Profeta David...

(77) En esta tienda, sólo vendemos mercancías al por mayor. Nada al por menor.

9) Le schéma en ellipse représente l'espace temporel. A ne pas confondre avec le cercle de coîncidence. 
(78) En cada esquina del campo se colocará una banderola cuya asta tendrá una altura de $1 \mathrm{~m} 50$ por lo menos.

(79) Aquí está la pobre Andrea trabajadora, hacendosa y por cierto nada fea.

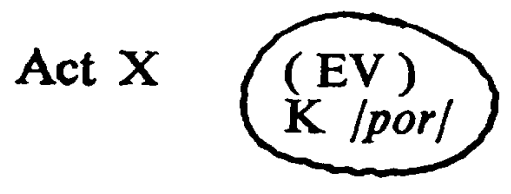

Il y a coïncidence entre l'événement et une caractéristique interne de sa réalisation $(\mathrm{K})$. Ce schéma est très productif : por suerte, por casualidad, por gorra vieja, por montones, etc...

Certaines expressions lexicalisées ainsi formées alternent avec une forme adverbiale en -mente : por demás demasiadamente, por fortuna afortunadamente, por fin finalmente, etc...

De la locution por menor dérivent le verbe pormenorizar et le substantif toujours pluriel los pormenores.

Référence.

(80) Yo siempre fui, por alma y por cabeza, español de conciencia, obra y deseo.

(81) Es de Lope. Lo dice el vulgo por las comedias de Lope de Vega cuyo verso es más llano y fácil que de otro.

(82) Tal vez la carne de perro no tenga muchos partidarios, digo por otros que quizá sea asi, por mi no, yo he comido perro hasta de vicio...

(83) Cada uno se había de enterrar por si, en su sepultura, porque los pecados del uno no se peguen al otro, que es ceremonia de moros.

(84) - Y para las cuotas de la reunión ¿Cuándo hablamos?

- Tranquilo, j hombre! lo dejamos para después.

Act X

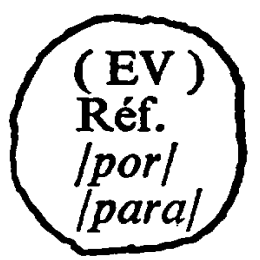

Il y a coïncidence entre l'événement et un référent (en lo que se refiere a, respecto a, a propósito de). Dans cet emploi, para apporte une connotation supplémentaire d'intentionalité de sorte que les deux prépositions ne sont généralement pas interchangeables $(80,84)$. En (83), effet de sens : por sí devient l'équivalent de solo. 
CONTENU SÉMANTIQUE DES PRÉPOSITIONS «POR 》 ET « PARA » 579

\section{Position-fonction.}

Dans cet emploi le potentiel COINCIDENCE de por est exploité en association avec RELATIVITÉ.

(85) Con su testamento nos reconoce por hijos legitimos a los tres hermanos y nos nombra por herederos universales, en primer lugar a vos, en segundo a mí, y en tercero a Nicolás, cada uno por el orden de la edad.

(86) Supo que había en Segovia un licenciado Cabra que tenía por oficio de criar hijos de caballeros.

(87) En dos consonantes ninguna dición acaba, salvo si pronunciamos como algunos escriven segund, por según; $i$ cient, por ciento: grand, por grande.

(88) El cielo quiero como papel

la mar quiero por tinta

los árvoles por péndolas para escribir mis lágrimas.

(89) El primer toro, que no pasaba por manso, era un toro de toreo de adorno, de hacer como que se torea.

(90) Yo soy toro en mi rodeo siempre me tuve por güeno salgan otros a cantar

y torazo en rodeo ajeno y si me quieren probar $\checkmark$ veremos quién es menos.

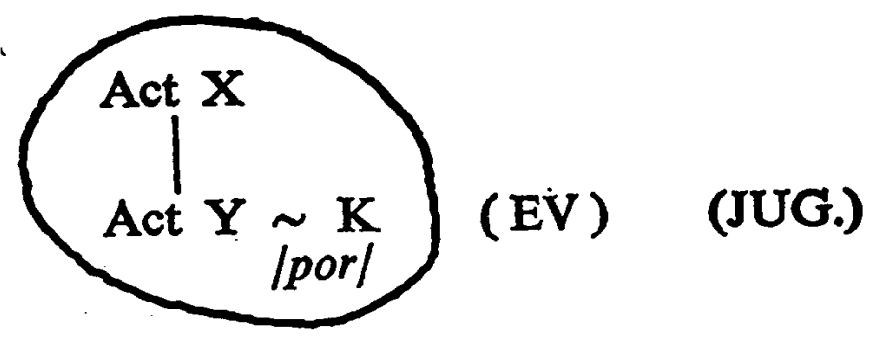

Deux actants $(85,87,88)$ ou un actant et une caractéristique $\mathrm{K}$ $(89,90)$ coïncident dans une même position-fonction où ils sont mis en équivalence.

En (86), ce sont deux événements qui sont mis en relation à travers deux nominaux.

En ce qui concerne por favor, ce syntagme est lexicalisé dans sa Jonction modale, laquelle prédomine sur l'emploi POSITION-FONCTION.

(91) ¿Qué quiere usted ? Cosas de Monseñor Perdomo !... Cuando yo supe que pensaba prohijar una candida- 
tura, le hice llamar y le mostré la conveniencia de abstenerse, de no opinar en este asunto y menos de recomendar a nadie.

Là apparaît la lexicalisation prohijar porhijar.

En liaison avec l'emploi modal de verbes comme tener, dar, quedar, pasar, etc., la coïncidence est dépendante du jugement exprimé par les verbes $(89,90,92)$.

(92) Casando el don Braga su hija con otro de su jaéz, siendo tuerta, la vendió por derecha. derecha).

Ici la modalité passe même dans la préposition (como si fuera

\section{III - Potentialite semantique Relativité.}

En relation avec cette potentialité tous les emplois de por et para relèvent du domaine notionnel.

Para

Attribution.

(93) Filomeno afirmó que tales molinos en nada parecian gigantes, y para gigantes de verdad habla unos, en Africa, tan grandes y poderosos, que jugaban a su antojo con rayos y terremotos.

(94) ¡Qué chiquita para más cochina !... Parece que te arrastraras por el suelo todo el día.

(95) 'Qué varón para beber! Baco quedaba a la saga, un chivato desmañado !... y Noé, una zapatilla rusa.

Act $\mathrm{X}$ $\mathrm{K} /$ paral

Dans cet emploi para établit une relation entre un actant et une caractéristique $K$ qui lui est attribuée. Cette relation est associée à une modalité d'intensif ; ainsi on pourrait paraphraser en (95) : « era un grandísimo borracho ".

Adéquation.

(96) No he visto gaucho más quiebra para retrucar, iahijuna!

(97) $P a^{\prime}$ qué quiero los dineros - si no me sirven pa' na' - salud es lo que quiero.

(98) ... de tal género de vida - se vienen a fastidiar, que no nacieron los hombres - para coser ni lavar. 
CONTENU SÉMANTIQUE DES PRÉPOSITIONS «POR » ET «PARA » 581

(99) Esto sí que es para caerse de espaldas, para morirse de risa.

(100) Dicen que era de muy buena cepa y según él bebia es cosa para creer.

(101) Para muestra basta un botón.

(102) Y la Torre Eiffel ha dejado, desde hace tiempo de ser un portento. Asunto para pisapapeles, si acaso.

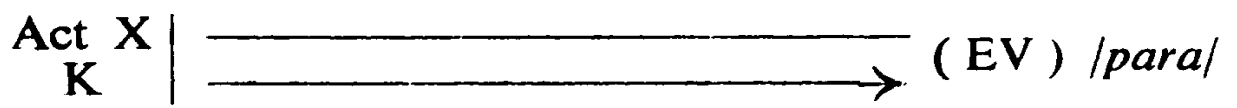

Cet emploi découle des potentialités RELATIVITÉ et DIRECTION-INTENTION.

Para établit une relation d'adéquation d'un actant ou d'une de ses caractéristiques à un événement. Ces sens diffèrent selon les relations de puissance mises en œuvre.

\section{Aptitude.}

Deux possibilités :

1) Relation entre un actant doté de puissance et un événement où cet actant est agissant (96 et 98)

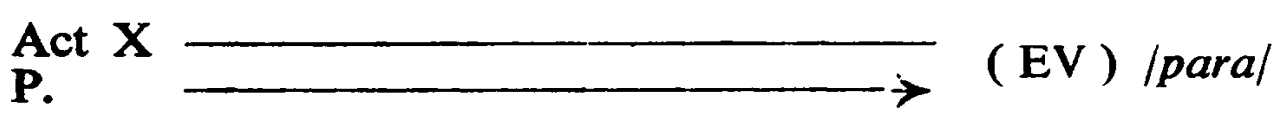

2) Relation entre un actant doté de puissance, qui peut être instrumental (97) ou causatif (99), et un événement dont le sujet est un actant $Z$ n'intervenant pas directement dans la relation.

Act $\mathrm{X}$

P.

(EV) /para/ (Act Z)

\section{Adéquation.}

Relation entre un actant non-puissant et un événement où l'actant puissant peut être explicitement énoncé $(97,98,99)$.

Act $\mathrm{X}$

(EV) /para/ Act Z

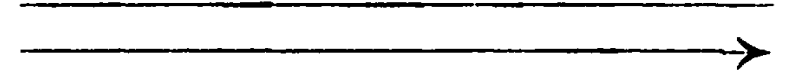

$P$.

La présence de como préposé à para renforce la part de la potentiaé RELATIVITÉ et affaiblit celle de DIRECTION-INTENTION. litnsi en (99) on pourrait avoir : es como para atacarse de risa.

Ai Si para relève de la seule potentialité DIRECTION-INTENTION, 
il signifie bénéfactif : esta falda es para Rosa. Como préposé apporte la potentialité RELATIVITÉ : esta falda es como para Rosa (adéquation : ( $\mathrm{q}$ qué bien le sentaría a Rosa !).

(103) $1,2,3-4,5,6-7,8,9$ - Para 12 faltan 3.

(104) iApúrate Domitila! Diez para las cuatro! se nos va el carro...

Un cas particulier de cette relation s'exprime avec le verbe faltar qui marque la non-adéquation entre les deux termes mis en relation (103). En (104) la structure de non-adéquation : faltan diez para las cuatro, est occultée par l'ellision du verbe. On peut penser ici à un emploi allatif.

Opposition ${ }^{11}$.

(105) Para ser la primera vez salió bien jojala sigan actuando con entusiasmo!

(106) Para los años que tiene es demasiado inocentón el niño Jacobo.

(107) Tanto me suplicaste para que a la hora de los loros no me dieras bola, ni una mirada siquiera.

(108) Podías aprender de él que buenos cuartos me cuestas para que luego seas más bruto que el hijo de la lavandera.

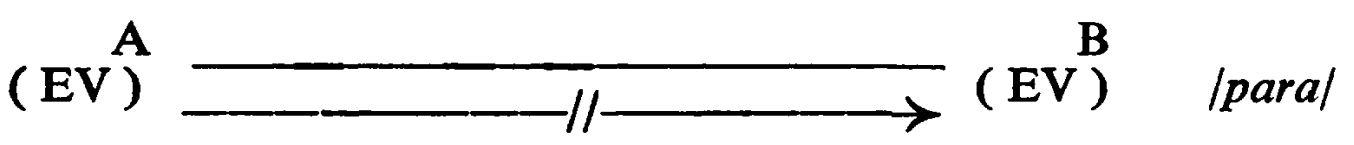

Para sert ici à placer dans une relation de dépendance deux événements qui se situent alors dans un rapport contrastif, la conséquence é:ant opposée à celle que l'on attendait. "Por ser la primera vez salió bien " donne un sens divergent où interviennent de la cause et de la concession (por causatif).

Dans les exemples $(106,107,108)$, il n'y a pas de possibilité que l'événement A soit la cause de B; et «por ende », on n'emploiera pas por.

Jugement.

(109) IQué señor tan buen cristiano, tan político y cumplido!

11) Représent6 par: (c.. por concession, p. 515). 
CONTENU SÉMANTIQUE DES PRÉPOSITIONS 《POR 》 ET « PARA » 583

- Pues es para mi marido el hombre más chabacano.

(110) Las palabras protestante, judio, masón, hereje y ateo eran para ella, sinónimos y no querían decir nada.

(111) Por algo la llaman la alemana... Pero esto es un grandísimo disparate... pues aquí se llama Giuseppa Pircher y para mi que se acuesta con su Alteza el Príncipe de Darmstadt.

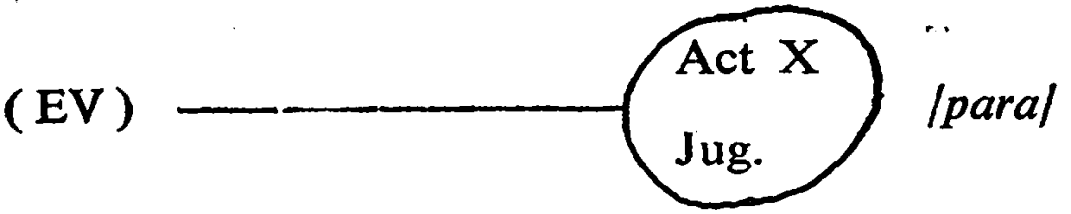

Para met en relation un événement et un actant $X$ qui porte un jugement sur cet événement. Aucune marque de modalité n'apparaît, l'actant et son jugement sont complétement coïncidents. La préposition apparaît obligatoirement associée à un nominal (nom propre, substantif ou pronom personnel). En (111) le syntagme ainsi formé a la valeur syntaxique d'un verbe modal et amène une proposition complétive.

Por

Permutation.

(112) En días anteriores se ajustó un cange de prisioneros Prusianos y Saxones por Franceses, y se daban dos de éstos por cada Alemán.

(113) ... No dejes lo ganado por lo que has de ganar; si dejas lo seguro por inseguro azar, no tendrás lo que quieres, te podrán engañar.

(114) Sacó un maravedí de la bolsa y mandó que fuese por él de vino a la taberna.

(115) Lluvia

Lana flor por ojo

flor por nube

flor $\overline{\text { por }}$ noche.

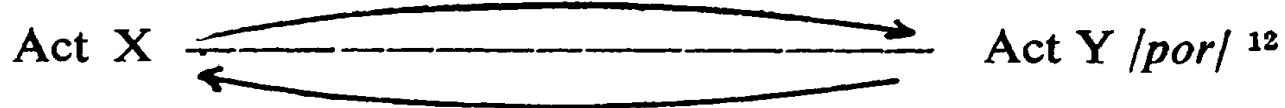

Une relation arbitraire ou codifiée s'établit entre deux termes et rend possible leur permutation. De là on arrive aux notions d'échange, de don et contre-don, de troc, prix, salaire. 12)

12) Flèches marquant la permutation; elles sont à distinguer de DIRectron- 


\section{Distribution.}

(116) 7 de Octubre. Navegó a su camino al Oeste, anduvieron 12 millas por hora.

(117) Procuré siempre que los subprefectos gratificasen a los indios, hice que como postillones de los correos se les abonara un real por legua.

(118) Les respondemos a nuestro mejor modo: Por cada huérfano una escuela

un jardin una palma

otra bocanada de viento

Por cada mentira una verdad. de futuro

Act $\mathbf{X}$ Act $\mathrm{Y} /$ por/

Il s'agit d'une relation d'attribution entre actants, combinée à une répétition théoriquement illimité et qui s'énonce : chaque fois qu'il y a Y (marqué por), il y a X. C'est ce qui est énoncé dans treinta por ciento, dans la lexicalisation porcentaje ou dans la notation rythmique : tres por cuatro, siete por ocho, etc...

Succession.

(119) Ese día, en el Instituto, estuvimos revisando punto por punto las conclusiones que presentábamos en el análisis de las preposiciones.

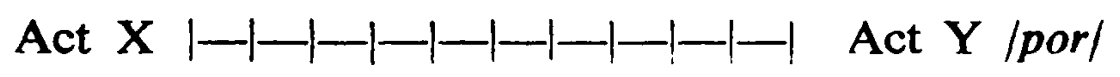

Por marque une relation de succession entre deux unités données par le même lexème (toujours au singulier). Cette relation peut se répéter sans limitation : página por página, palabra por palabra, uno por uno (mais, de $a$ dos, ou de dos en dos).

\section{IV - Potentialite semantique puissance.}

Les occurrences de para sont très réduites et se limitent à l'emploi d'intercession (voir plus bas). Les emplois de por se situent tous dans le DOMAINE NOTIONNEL.

Por

Agentiel

(120) Os fue dada por Dios una virtud tremenda, el ganar el botín y abandonar la tierra.

13) Effet de sens: menudamente. 
CONTENU SÉMANTIQUE DES PRÉPOSITIONS «POR » ET «PARA 》 585

(121) La mujer africana que haya sido despedida de su empleo 4 veces en el plazo de 1 año por llegar tarde al empleo, puede ser detenida en cualquier momento sin orden de arresto por un policía que tenga razones para creer que es una ociosas.

(122) - - Tengo sueño », repetía el disfrazado

- Déjese arrullar por el compás de los remos $\$$.

Act X /por/ (EV) Act Y

P.

Por marque l'actant initiateur et générateur de l'action, toujours en liaison avec un verbe au passif.

C'est aussi la marque du multiplicateur dans l'opération arithmétique : 2 por 3 son 6 .

Médiateur.

(123) Hoy vuelvo a este cariño malo

y se ve por tu reír

que aún no sabes cuánto he llorado.

(124) Al hombre por la palabra y buey por el cuerno.

(125) El indio, por los ademanes y meneos, que con manos y rostro le hacian como a un mudo, entendia que le preguntaban mas no entendía lo que le preguntaban.

(126) Yo te estimaría que vos por ti mismo o por algun amigo le persuadieses a que viniese.

(127) Las brigadas de culturización indigena tendrán la misión de educar a las masas de indígenas adultos... por medio de charlas y conferencias dictadas en su propio idioma...

(128) Los gitanos confesaron que se habian orientado por el canto de los pájaros.

(129) Por nuestro Señor que nos está viendo y escuchando allá arriba, por San Nicolasito que es nuestro patrono...

(130) Présteme 2000 pesos Adrián, por vida suya.

(131) Llévame por piedad a donde el vértigo con la razón me arranque el corazón.

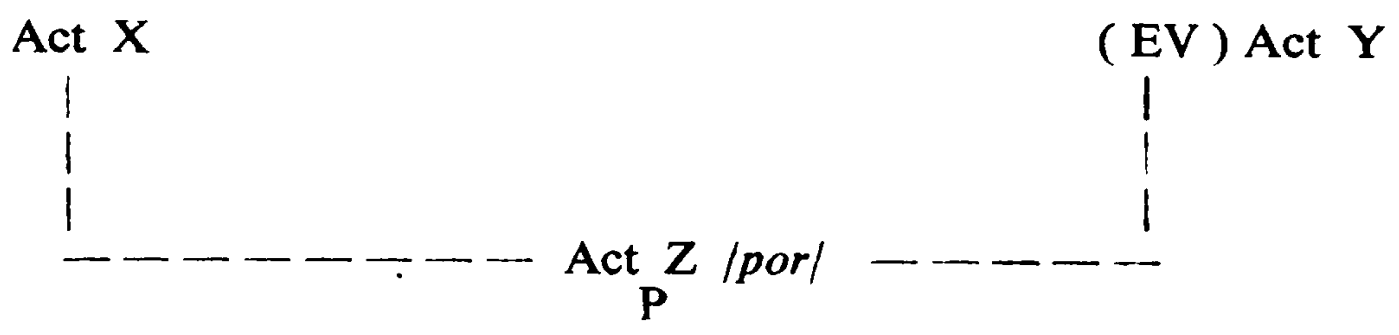


L'actant supplémentaire $Z$, marqué por, est générateur de l'événement mais non initiateur ; il médiatise la participation de $\mathrm{X}$, initiateur de l'événement.

En fonction du potentiel PUISSANCE, on peut distinguer les sens suivants :

Instrumental. $(123,124,125)$

Le médiateur est caractérisé par une forte capacité génératrice et se rapproche du causatif.

Intermédiaire. $(126,127,128)$

La capacité génératrice est moindre et le terme marqué a valeur d'auxiliaire dans la réalisation de l'événement.

Intercession. (129, 130, 131)

Faible capacité génératrice, le terme marqué intervient de façon très indirecte, par l'invocation adressée à la puissance de son nom. Cet emploi est très productif dans les serments et jurons : (129), por Dios, por el Dió, por mi madre, por mi fe, por la cruz, por la p... que te parió etc...

On repère quelques lexicalisations : pordiosear, pordiosero, porviche (= por vida de).

Para POR Dios.

Comme le fait remarquer Bello, para alterne avec por : PARdizl

(132) Pa Dios bendito.

(133) Callen la boca y váyanse con Dios, si no por mi santiguada que arrojo el bodegón por la ventana.

(134) Para mi santiguada que si yo fuera camino con ellos que nunca les fiara la bota.

(135) Pensóse don Simueque que me engañaba con su hija la tuerta, y por el Dió, contrahecho soy de un lado.

(136) Piensa don Braga que con su hija la tuerta me engaña. Pues para el Dio, hermano, que soy contrahecho de un lado.

Le principe d'organisation observé dans la description des emplois nous permet de tenter la définition contrastive des deux prépositions. Nous envisagerons dans les tableaux suivants leurs emplois communs, puis exclusifs. 
CONTENU SÉMANTIQUe DES PRÉPOSITIONS «POR 》 ET « PARA 》 587 Emplois communs :

\begin{tabular}{|l|l|}
\hline $\begin{array}{l}\text { POTENTIALITÉS } \\
\text { SEMANTIQUES }\end{array}$ & por, para \\
\hline $\begin{array}{l}\text { DIRECTION- } \\
\text { INTENTION }\end{array}$ & $\begin{array}{l}\text { pré-inchoatif } \\
\text { futur } \\
\text { finalité } \\
\text { bénéfactif }\end{array}$ \\
\hline COINCIDENCE & $\begin{array}{l}\text { locatif temporel } \\
\text { duratif } \\
\text { référence }\end{array}$ \\
\hline RELATIVITÉ & intercession \\
\hline PUISSANCE & \\
\hline
\end{tabular}

Emplois exclusifs :

\begin{tabular}{|c|c|c|}
\hline Potentialité & Para & Por \\
\hline $\begin{array}{l}\text { DIRECTION- } \\
\text { INTENTION }\end{array}$ & $\begin{array}{r}\text { Allatif } \\
\text { 二 } \\
\text { - }\end{array}$ & $\begin{array}{l}\text { inchoatif } \\
\text { causalité } \\
\text { causalité intentionnelle } \\
\text { concession } \\
\text { recherche }\end{array}$ \\
\hline COINCIDENCE & - & $\begin{array}{l}\text { locatif spatial } \\
\text { manière } \\
\text { position-fonction }\end{array}$ \\
\hline RELATIVITÉ & $\begin{array}{l}\text { attribution } \\
\text { adéquation } \\
\text { aptitude } \\
\text { opposition } \\
\text { jugement } \\
\quad \text { - } \\
\text { - }\end{array}$ & $\begin{array}{r}- \\
= \\
- \\
\text { permutation } \\
\text { distribution } \\
\text { succession }\end{array}$ \\
\hline PUISSANCE & - & $\begin{array}{l}\text { agentiel } \\
\text { instrumental } \\
\text { intermédiaire }\end{array}$ \\
\hline
\end{tabular}

14) La marginalite de l'emploi allatif de por (voir plus haut) fait que nous ne le retenions pas ici. 
On dénombre dans le corpus 14 emplois exclusifs de por contre 6 de para. D'ailleurs les occurrences de por sont nettement plus fréquentes. En outre la potentialité PUISSANCE de para n'est mise en œuvre que pour le sens isolé d'intercession.

La productivité relative des potentialités peut être dégagée ainsi :

\begin{tabular}{|l|cc|}
\hline & para & por \\
\cline { 2 - 3 } DIRECTION-INTENTION & 5 & 9 \\
\hline COINCIDENCE & 3 & 6 \\
\hline RELATIVITÉ & 5 & 3 \\
\hline PUISSANCE & 1 & 4 \\
\hline
\end{tabular}

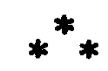

Si l'on s'intéresse aux formes de ces prépositions dans la langue ancienne, on apprend que por coexistait avec per, qui était très largement utilisé (cf. A. Zamora Vicente et R. Lapesa).

Por vient des prépositions latines pro (par métathèse) et per qui se sont confondues dans la majorité des langues romanes, et para de pro ad (pro ad > pora > para, cf. Menéndez Pidal) ou de per ad ( $>$ pera > para, cf. Hanssen).

En latin classique per apportait les sens localisation spatiotemporelle (transit, occupation de l'étendue spatiale et durée), médiation (instrumental, intermédiaire intercession), cause et manière ; et a marqué plus tard, en relation avec le sens médiation, le complément du verbe passif. (cf. E. Bourciez).

Pro marquait la localisation spatiale orientée, la cause, le bénéfactif, la coïncidence notionnelle de fonction, l'échange et l'adéquation.

Enfin ad donnait entre autres les sens allatif, locatif spatio-temporel, finalité, causatif, intentionnel, bénéfactif, adéquation, coïncidence notionnelle de référence.

Les emplois de ces trois prépositions latines s'organisent selon les potentialités sémantiques dans le tableau ci-dessous, où apparaissent également les emplois corrélatifs de por et para. 


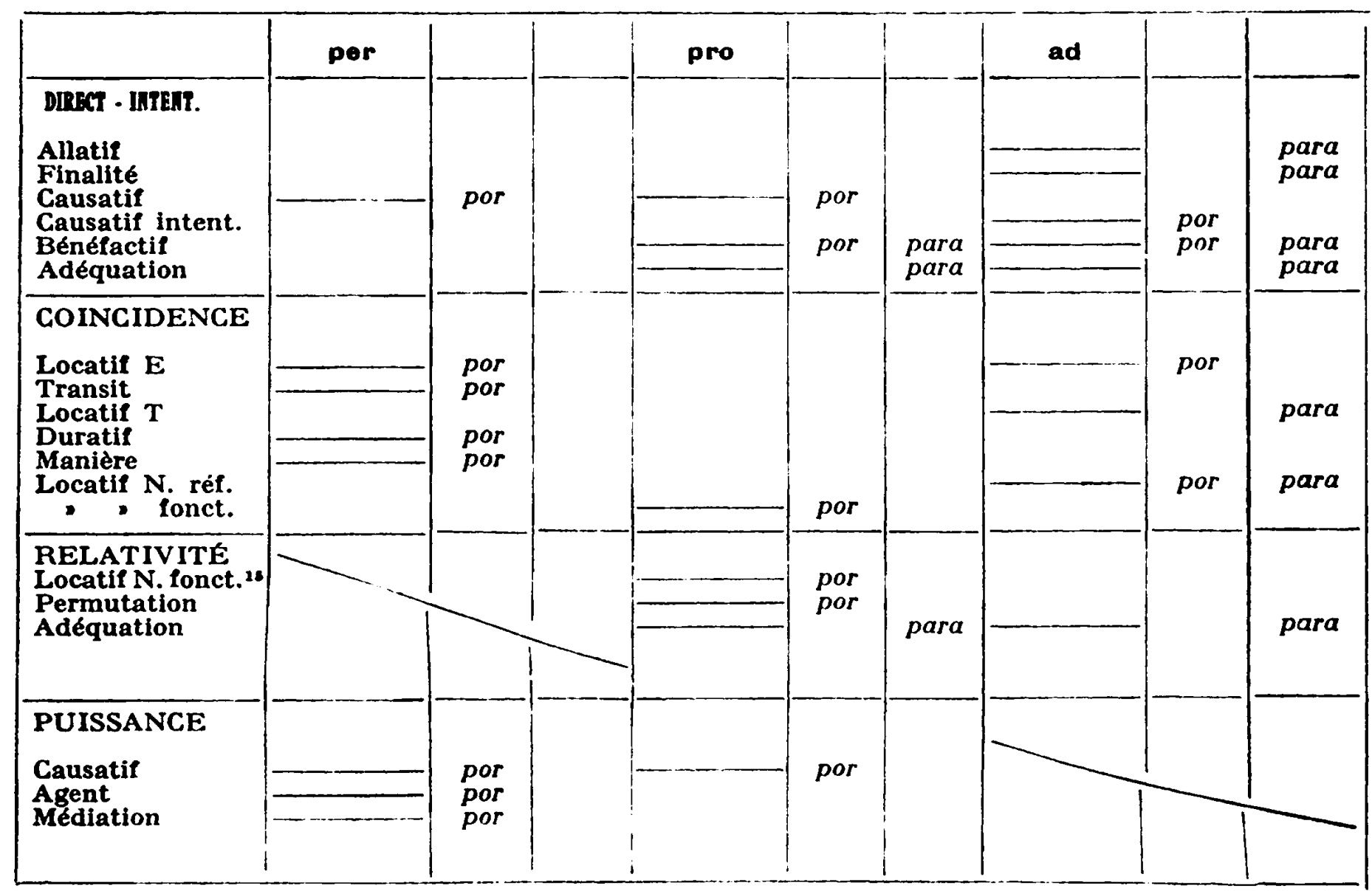

Ce tableau rend manifeste une certaine affinité sémantique entre pro et ad, ce qui semble confirmer la thèse de Menéndez Pidal : c'est vraisemblablement par le truchement du sens bénéfactif de pro que la préposition por a marqué la finalité ; par la suite c'est para qui s'est spécialisé dans cet emploi, en contraste avec por qui marque plutôt ce que nous avons analysé comme causatif intentionnel encore que, comme on l'a vu, l'emploi finalité se maintienne de nos jours.

Remarquons aussi que per ne possède pas la potentialité RELATIVITÉ et que ad n'a pas PUISSANCE.

Tous les emplois de per et pro, sauf bénéfactif et adéquation (DIRECTION-INTENTION, RELATIVITÉ), sont marqués exclusivement par por. De son côté, para apparaît surtout en corrélation avec ad, ces deux prépositions présentant la majorité de leurs emplois en DIRECTION-INTENTION.

15) Locatif notionnel de fonction, adéquation et causatif apparaissent simultanément en deux potentalités, conformément à l'analyse des relations sous-jacentes. 
La préposition latine pro est lexicalisée en espagnol dans son emploi bénéfactif : par exemple, Asociación pro-juventud, hay que considerar el pro y el contra.

Le gallicisme por contra, apparu ces dernières années dans la presse espagnole, proscrit par les puristes et mal perçu par les locuteurs, calque le français par contre, où c'est l'emplor position-fonction de par qui est pertinent, alors qu'en espagnol, cet emploi de por est oblitéré par le bénéfactif ; si bien qu'on ressent une forte contradiction entre le bénéfactif à connotation positive (por) et négative (contra).

La recherche systématique du contenu sémantique des prépositions permet, d'une part, de rendre compte de l'ambiguïté sur laquelle repose le sens de ccrtaines expressions, par exemple un grand nombre de proverbes ou des plaisanteries fondées sur des jeux de mots, et d'autre part, fait apparaître également, dans certains cas, deux ${ }^{16}$ emplois intégrés en un seul sens c'est-à-dire répondant à une seule image, ou encore relevant d'une seule interprétation. Les syntagmes ainsi formés peuvent être analysés de façon plus précise et exhaustive.

(137) Por más señas tiene a su lado izquierdo un jarro desbocado que cabe un buen porqué de vino, con que se entretiene en su trabajo.

Ici, el porqué ${ }^{17}$ intègre les emplois causatif et prix dans la lexicalisation.

(138) No puede ninguna justicia entrar alli (a la galera), $y$, si por malos de sus pecados entra, o le echarán al remo o le darán un trato, por manera que en las galeras es a do se van los buenos a perder y los malos a defender.

Emplois intégrés dans ce syntagme : causatif et échange.

... Quince apsaras de voces roncas, frente a los fumaderos, saltan sobre los que duermen apilados en las aceras, ripiando a los pasantes por la camisa.

Ici, la camisa est à la fois le moyen et le lieu de la réalisation de l'action ; locatif spatial et instrumental sont les emplois intégrés.

(140) Creo ... en Jesucristo, su único hijo, Nuestro Señor que fue concebido por obra y gracia del Espíritu Santo...

Emplois intégrés : agent et instrumental ; d'ailleurs peut-on dissocier dans l'acte de création, outil et conception?

19) Selon notre démarche, rien ne s'oppose à ce qu'il y en ait davantage.

17) - Con el acento en la última se hace nombre y se toma por PREcio y causa do lo que se hace (souligne par nous) », Gonzalo Correas, Vocabulario de refranes $y$ frases proverbiales. 
CONTENU SÉmANTIQUe Des PRÉPOSITIONS 《POR » ET « PARA 》 591

Laissons la parole au Poète :

«Dans ces murs voués aux merveilles

j'accueille et garde les ouvrages

de la main prodigieuse de l'artiste

égale et rivale de sa pensée

l'une n'est rien sans l'autre. »

(141) Iban dos caminando, y vieron una huerta con repollos y coles. Dijo el uno: \&Qué buenas verzas! \$Andadas algunas leguas adelante responde el otro « Para con tocino ».

Dans cette locution qui s'applique à ce qui est dit ou fait hors de propos ou trop tard, les emplois intégrés sont la finalité et l'adéquation.

(142) Después que estuvo un gran rato echando la cuenta, por dias y dedos contando, dijo... nueve (panes) quedan y un pedazo.

Ici, la polysémie de la préposition permet un amalgame : por régit deux substantifs coordonnés ayant des emplois différents : por dias, distributif ; por dedos, locatif notionnel de manière, ce dernier étant lui-même la résultante d'un locatif spatial et d'un instrumental.

(143) Si un día coméis en la venta donde el ventero cariacuchillado ... os vende gato por liebre, el macho por carnero, la cecina de rocín por de vaca, y el vinagre aguado por vino puro; $\bar{a}$ la noche cenáis en casa de otro huésped, donde os dan el pan por pan y el vino por vino.

Il s'agit d'un cas un peu différent : por répond ici à un seul emploi position-fonction auquel s'ajoute une modalité intégrée (désir de tromper).

Il va de soi que ces exemples n'illustrent que certaines possibilités d'emplois intégrés. On pourrait continuer ainsi, mais la recherche d'autres emplois ne ferait que confirmer l'analyse proposée.

La polysémie de la préposition donne lieu également à des cas d'ambiguité, où le syntagme peut être compris en se référant à deux emplois différents, et tous deux acceptables.

(144) (...) el hombre que navega, si no es por descargo de su consciencia o por defender su honra o por amparar la vida, digo y afirmo que ... le pueden atar por loco. 
Dans cet exemple, la préposition rend possible l'interprétation par le causatif (porque está loco) ou/et par position-fonction (como, en tanto que loco).

(145) Díganle también (a mi mujer) que si el que va a nacer nace varón, que le pongan José Arcadio, pero no por el tío sino por el abuelo.

Ici deux interprétations sont possibles, soit, parce qu'ils portaient ce nom, causatif ; soit, en pensant à eux, référence.

On repère les mêmes emplois dans les $\lrcorner$ paroless d'un corrido :

¿Dónde vas Román Castillo,
dónde vas, pobre de ti ?
Ya no busques más querellas
por nuestras damas de aquí
ya está herido tu caballo...

(147) Te hablan por mi las piedras aporreadas

las alas de pájaros sin cielo

Te habla por mi el color de los pájaros sin cielo el rebaño de ovejas taciturnas.

En (147) on peut interpréter, soit par position-fonction (à ma place), soit par bénéfactif (en ma faveur).

(148) El capitán no consiguió desenvainar sino media tizona ... Viendo lo cual, vinieron todos por él, y uno, medio le rebañó la pierna izquierda, derrumbandose él boca abajo.

On discerne comme à la curée, l'idée de débusquer la proie, recherche, et de lui venir sus, locatif spatial.

(149) Le contaré que Rosarito llega pasado mañana. (...) lo que pienso es que por angas o por mangas esto tiene que costarme algún dinero y que ese dinero me va a costar un quebradero de cabeza.

Le locatif notionnel de manière est l'emploi qui donne son sens à cette locution. On discerne également un emploi locatif spatial dans por mangas, avec un jeu sémantico-lexical sur por angas/ por ancas.

(150) Por la boca muere el pez.

C'est la polysémie de por donnant lieu à deux interprétations : 
CONTENU SÉMANTIQUe DES PRÉPOSITIONS «POR » ET «PARA 》 593

causatif et instrumental, qui permet de tirer la moralité du proverbe.

On peut l'opposer à :

(151) El hombre por la luenga.

où por ne répond qu'à l'emploi causatif ; là on ne propose pas un enseignement, mais on généralise une caractéristique.

Mais on peut faire des jeux de mots même dans un emploi unique, ainsi cette plaisanterie classique reprise au compte du président Abadía Méndez, (Colombie 1930), où le jeu se fait sur le seul emploi futur, entre la lexicalisation por venir et por + infinitif.

(152) - ¿En qué se parece el doctor Abadía a una negra en cinta?

- iEn que tiene un negro por venir...!

On a vu plus haut que por est lié à un plus grand nombre d'emplois et a donc une fréquence d'utilisation supérieure à celle de para, ce qui explique que ce tour d'horizon de la polysémie se soit fait essentiellement autour d'exemples utilisant por (pour cette partie du travail, le corpus ne présente qu'un exemple avec para (141), ce qui n'exclut pas bien sûr, la possibilité d'autres emplois polysémiques de para... et de por).

La méthode descriptive que nous avons observée a permis de distinguer pour une seule occurrence de la préposition deux emplois, intégrés ou dissociés ; mais il faut souligner qu'il n'y a aucune contrainte de choix entre eux, et qu'au contraire ils forment un ensemble qui suggère quelque chose en plus, qui élargit le sens. Voilà l'aspect positif de l'ambiguïté : elle contribue à la richesse du discours - non scientifique - elle est à la source de la poésie, de l'humour, de la fantaisie, elle est toujours présente dans la création littéraire.

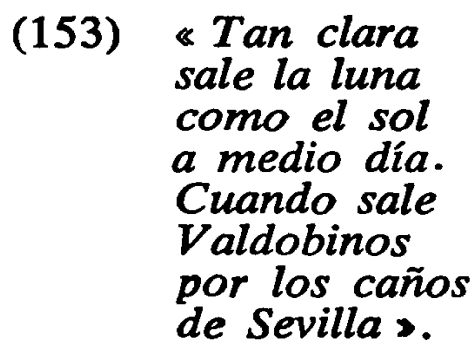

\author{
D. NEYROD, Y. WELLER, \\ Paris-VII / C.N.R.S., U.A. 1026.
}




\section{REFERENCES DES EXEMPLES}

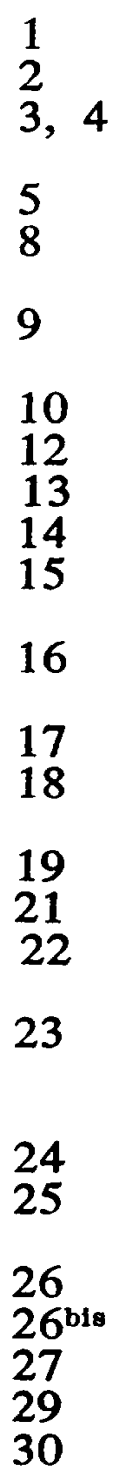

Dos puntas tiene el camino. Cueca cuyana.

Jorge Luis BORGES, El libro de arena.

Un marido entre dos mujeres. Novela anónima en ladino, Biblioteca nueva Sefarad.

Joaquín WAYRU, Cuentos de mi pueblo. El Señor Alcalde. El molinero y el cura. Romance. Manuel Alvar, Poesía tradicional de los Judíos Españoles.

Cueca boliviana. Cochabamba. Recueillie et publiée par A. Paredes-Candia, Poesía popular boliviana.

Indications pour la préparation de la chicha.

Juan ACEveDo, Aventuras del Cuy (B.D.).

Carlos BARRAL, Retrato a la sanguínea sobre cartón gris. El Quijote de Avellaneda.

M. DE Cervantes SaAvedra, El Ingenioso Hidalgo don QUiJOTE DE LA MANCHA.

Ramón Trujillo, Nota para un estudio de las preposiciones españolas.

Rafael AlBERTI, La arboleda perdida.

Pablo NerudA, Veinte poemas de amor y una canción desesperada.

Gabriel García Márquez, Cien años de soledad.

Gregorio MARTínEz, Canto de sirena.

Refrán. MARTínez KLEISER, Refranero general ideológico español.

Copla. D. Juan del Valle y Caviedes (XVI), Voces y giros del habla colonial española:D. Juan del Valle y Caviedes. Maria Leticia CACERES A.C.I. Antonio MACHADO, Juan de Mairena.

Presse espagnole 1983. Cité par BELOT, Lexique de l'espagnol contemporain.

Flamenco. Traditionnel Espagne.

Juan de EnCinA, Poesía lírica y cancionero musical.

Martín ADÁN, La casa de cartón.

Estanislao DEL CAMPO, Fausto.

Octavio PAZ, Traduction d'un sonnet de Th. de Viau, transcrit par Baudelaire (Mon coeur mis à nu):

«Je viens pour rebaiser le plus beau des amants; Traditionnel. Bolivie. je viens pour remourir de tes embrassements. \$

Sor JUANA INÉs DE LA CRUZ, Censura a los hombres que acusan en las mujeres lo que ellos mismos causan.

"Chiste > Espagne.

Mario Vargas Llosa, ¿Quién mató a Palomino Molero?

Juan RUIZ, ARCIPRESTE DE HiTA, Libro de buen amor.

Gonzalo CORREAS, Vocabulario de refranes y frases proverbiales.

César Vallejo, La rueda del hambriento. Poemas Humanos et Retablo. Los Heraldos Negros. 
CONTENU SÉMANTIQUE DES PRÉPOSITIONS «POR 》ET « PARA » 595

39b: Fray Tomás de la TORRE, Diario del viaje de Salamanca a Ciudad Real (XVI).

40 Kantiga. Traditionnel, džudezmo.

41

42

Francisco de Quevedo, La hora de todos.

M. Zapata Olivella, Changó, el gran putas.

44

45

Candelario OBEso, Canción del boga ausente.

46

Son jarocho. La bamba. Traditionnel Mexique.

49

Proverbe. Džudezmo.

El Capitán Alonso de Contreras, Autobiografía.

Miguel Delibes, Cinco horas con Mario.

Chabuca Granda, La flor de la canela (Vals criollo).

51

Martín ADÁN, La casa de cartón.

Eugenio de SAlazAR, Carta al licenciado Miranda de Ron. Joropo. Traditionnel. Colombie.

Leonidas RiverA, «Don Máximo», Charlas de evocación taurina.

C. Vallejo, La rueda del Hambriento. Poemas Humanos.

Receta de cocina. Frejoles colados.

Rafael AlbERTI, La arboleda perdida.

El País. Madrid 86.

60

61

62

63

64

65

R. Pabón y PaBón, Asi tomamos la embajada.

Proverbe. Espagne.

Ariel RAmírez, Zamba de Balderrama.

M. de Cervantes, Coloquio de Cipión y Berganza.

Fray Bartolomé de LAS CaSAs, Los cuatro viajes del Almirante.

Gabriel García Marquez, Cien años de soledad.

69

E. SAPORTA Y BEJA, Entorno de la torre blanca.

Alabao. Canto funerario. Traditionnel. Colombie.

Tango. Traditionnel. Argentine.

Recette de cuisine. Ajiaco de gallina.

Cantique.

Camilo José Cela, Don Camilo 1936.

Gazeta de Lima (Nov. 1793).

Ricardo Palma, Tradiciones peruanas.

Canciller Pero López de Ayala, Crónicas.

Reglas oficiales del fútbol.

Romances de ciego. Traditionnel Espagne.

Rubén Darío.

82

83

Gonzalo CoRreas, Vocabulario de refranes y frases proverbiales.

2 G. Martínez, Canto de sirena.

Catalina de Villoda (de Vélez), Rito musulmán, in Jeanne VIDAL, Quand on brâlait les morisques. M.B. Fontanella DE Weinberg, El voseo en B.A. en las dos primeras décadas del siglo $X I X$.

Fr. de Quevedo, El Buscón.

Antonio de Nebrija, Gramática de la Lengua Castellana.

89

Kantiga. Džudezmo.

Gregorio Corrochano, ¿Qué es torear?

90 José Hernández, Martín Fierro. 


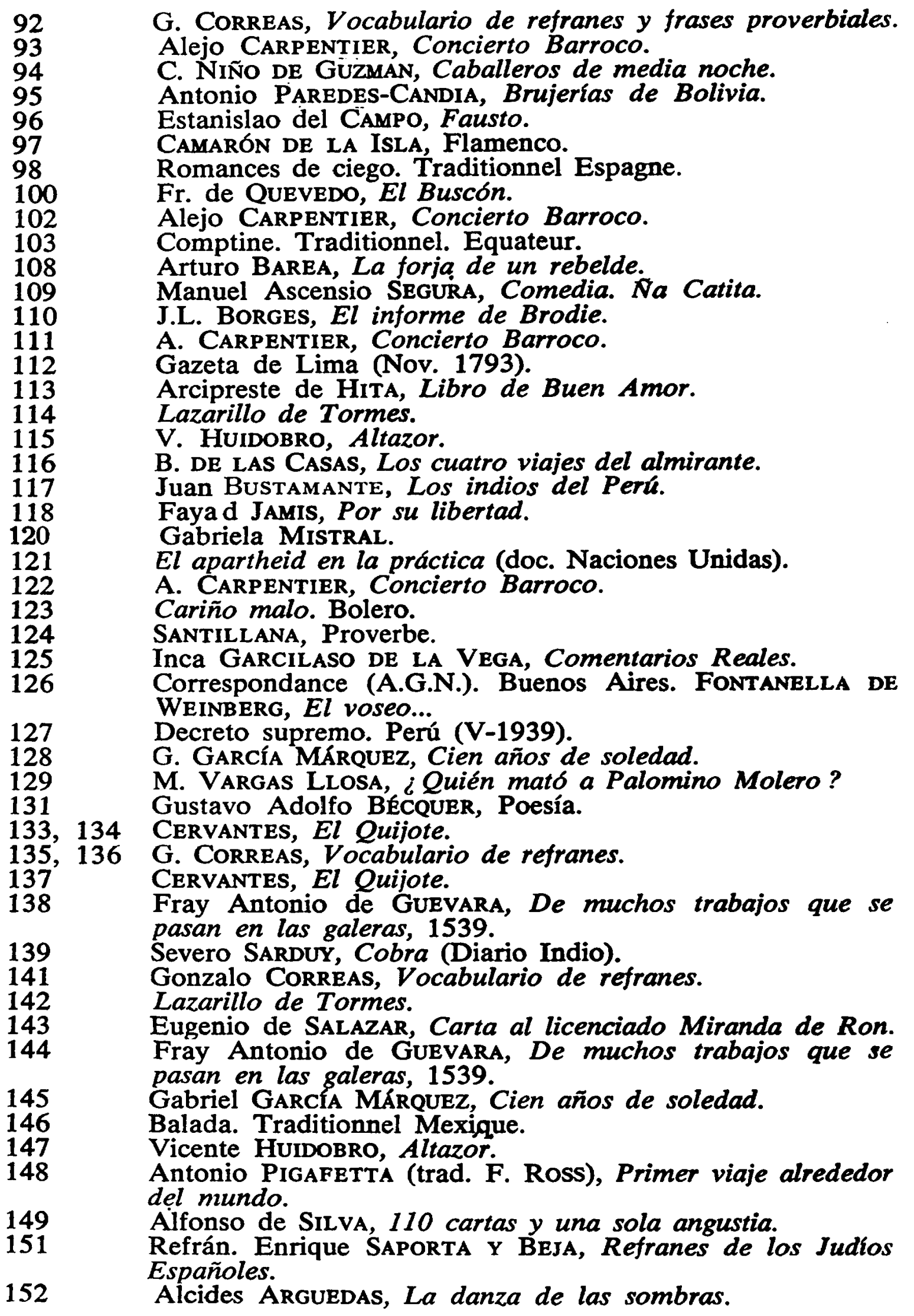


CONTENU SÉMANTIQUE DES PRÉPOSITIONS 《POR 》ET «PARA » 597

Chanson de María La Carnicera (María Aliger, de Deza), in Jeanne VIDAL, Quand on brûlait les morisques.

\section{BIBLIOGRAPHIE}

Alarcos Llorach Emilio (1984), Estudios de Gramática Funcional del Español, Madrid, Gredos, 1984.

BEINHAUER Werner (1958), Spanische Umgangssprache, Trad. española, Madrid, Gredos, 1978.

Bello Andrés \& Cuervo Rufino J. (1881), Gramática Castellana, Buenos Aires, Ed. Sopena, 1964.

BoURCIEZ Edouard (1910), Eléments de linguistique romane, Klincksieck, 1967.

Corominas Joan (1967), Breve Diccionario de la Lengua Castellana, Madrid, Gredos, 1967.

FreI Henri (1929), La grammaire des fautes, Paris, 1929.

HANSSEN F. (1911), Observaciones sobre la preposición " para», Bulletin Hispanique, XIII, 1911 ; (1945), Gramática histórica de la lengua castellana, Buenos Aires, 1945.

LAPESA Rafael (1980), Historia de la lengua española, Madrid, Gredos, 1980.

Menéndez Pidal Ramón (1939), Los Romances de América y otros estudios, Espasa Calpe, 1948 ; (1941), Manual de gramática histórica española, Madrid, Espasa Calpe, 1941 ; (1942), El idioma español en sus primeros tiempos, Madrid, Espasa Calpe, 1970.

Nebrija Antonio de (1492), Gramática de la lengua castellana, Madrid, Editora Nacional, 1980.

PotTIER Bernard (1962), Systématique des éléments de relation. Etude de morphosyntaxe structurale romane, Paris, Klincksieck, 1962; (1968), Lingüística moderna y filología hispánica, Madrid, Gredos, 1968 ; (1970), Gramática del Español, Madrid, ed. Alcalá, 1970; (1974), Linguistique générale. Théorie et description, Klincksieck, 1974 ; (1972), Introduction à l'étude linguistique de l'Espagnol, Paris, ed. Hispano-américanas, 1972.

Notre étude est redevable aux travaux de Bernard Pottier, à son cours en Sorbonne (Paris-III puis Paris-IV) et à son séminaire à l'EPHE (IV' section).

Real Academia Española, Gramática de la lengua española, Madrid, 1962.

Real ACademia Española, Diccionario de la lengua, Madrid, 1970.

Seco Manuel (1956), Diccionario de dudas y dificultades de la lengua española, Aguilar, 1970.

SePhiHa Haïm Vidal (1975), Théorie du Ladino. Additifs. In : Mélanges offerts à Charles Vincent Aubrun, Paris, ed. Hispaniques, 1975 ; (1977), L'agonie des Judéo-Espagnols, Paris, Ed. Entente, 1977 ; (1986), Le Judéo-Espagnol, Paris, Entente, 1986. 